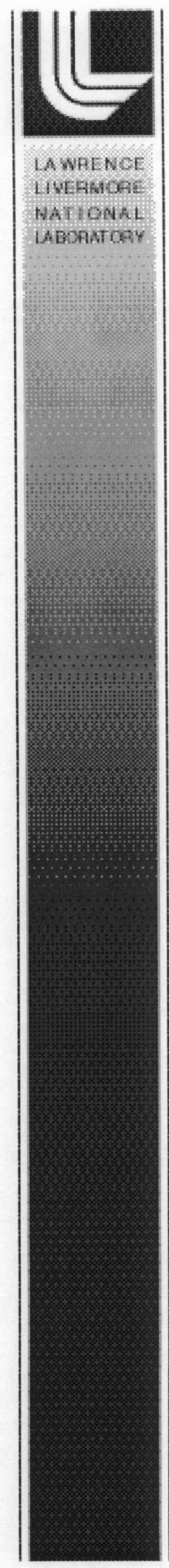

UCRL-JC-151802

\title{
Electrochemical Hydrogen Sensor for Safety Monitoring
}

L. P. Martin, A.-Q. Pham, R. S. glass

April 25, 2003

$14^{\text {th }}$ International Conference on Solid State Ionics, Monterey, CA, June 22-27, 2003 
This document was prepared as an account of work sponsored by an agency of the United States Government. Neither the United States Government nor the University of California nor any of their employees, makes any warranty, express or implied, or assumes any legal liability or responsibility for the accuracy, completeness, or usefulness of any information, apparatus, product, or process disclosed, or represents that its use would not infringe privately owned rights. Reference herein to any specific commercial product, process, or service by trade name, trademark, manufacturer, or otherwise, does not necessarily constitute or imply its endorsement, recommendation, or favoring by the United States Government or the University of California. The views and opinions of authors expressed herein do not necessarily state or reflect those of the United States Government or the University of California, and shall not be used for advertising or product endorsement purposes. 
Electrochemical Hydrogen Sensor for Safety Monitoring

L. P. Martin*, A.-Q. Pham, and R. S. Glass

Lawrence Livermore National Laboratory

Mail code: L-353

P.O. Box 808, Livermore, CA 94551

*Corresponding author: Phone: 925-423-9831, Fax: 925-423-7040, email: martin89@llnl.gov

\begin{abstract}
A hydrogen safety sensor is presented which provides high sensitivity and fast response time when operated in air. The target application for the sensor is external deployment near systems using or producing high concentrations of hydrogen. The sensor is composed of a catalytically active metaloxide sensing electrode and a noble metal reference electrode attached to an yttria-stabilized zirconia (YSZ) electrolyte. The sensing approach is based on the difference in oxidation rate of hydrogen on the different electrode materials. Results will be presented for a sensor using a sensing electrode of tindoped indium oxide (ITO). Response to $\mathrm{H}_{2}$, and cross-sensitivity to hydrocarbon and $\mathrm{H}_{2} \mathrm{O}$ are discussed.
\end{abstract}

PACS codes:

Keywords: Hydrogen, sensor, electrochemical, stabilized-zirconia, YSZ 


\section{INTRODUCTION}

A hydrogen safety sensor has been developed which provides high sensitivity and fast response time when operated in air. The target application for the sensor is external deployment near systems using or producing high concentrations of hydrogen. An example is within the passenger cabin in a PEM fuel cell powdered vehicle. Unintentional leakage of hydrogen gas into the passenger cabin would be detected by the sensor and suitable safety-action initiated (i.e. system shut-down). The hydrogen safety sensor is composed of a catalytically active metal-oxide sensing electrode and a noble metal reference electrode attached to an yttria-stabilized zirconia (YSZ) electrolyte. Sensing and reference electrodes are located next to each other on the same side of the electrolyte. The entire metaloxide/YSZ/metal combination is exposed to the test gas (i.e. no reference gas is required) and comprises an electrochemical cell for which the open circuit potential in air is sensitive to the presence of residual hydrogen.

This sensing approach is based on the difference in oxidation rate of hydrogen on the different electrode materials. In an electrochemical cell of this type, the generally accepted sensing mechanism at the electrodes can be expressed as a combination of simultaneous, competing oxidation-reduction reactions:

$\mathrm{H}_{2}+\mathrm{O}^{2-} \rightarrow \mathrm{H}_{2} \mathrm{O}+2 \mathrm{e}^{-}$

$1 / 2 \mathrm{O}_{2}+2 \mathrm{e}^{-} \rightarrow \mathrm{O}^{2-}$

In the presence of $\mathrm{H}_{2}$ in air, each electrode will reach a steady state potential related to the catalytic activity of the electrode material to the oxidation of $\mathrm{H}_{2}$, Eq. (1). For this sensor, the electrode materials were selected to have significantly different oxidation rates. This difference in oxidation rates creates a 
potential difference across the electrolyte which is easily measured and directly related to the concentration of hydrogen in the monitored environment. Results will be presented for a sensor using a sensing electrode of tin-doped indium oxide (ITO) and a YSZ electrolyte. The sensor is heated to the operating temperature using an integrated $\mathrm{Pt}$ resistance heater. Response to $\mathrm{H}_{2}$, cross-sensitivity to hydrocarbon and $\mathrm{H}_{2} \mathrm{O}$ are discussed.

\section{EXPERIMENTAL}

Sensors are fabricated on a laminated substrate with an integrated resistive heater screen printed onto one of the internal layers [1]. The exposed, top surface of the laminate has the reference and sensing electrodes deposited onto the exposed YSZ. The reference electrode is applied using commercial conductive paste. The sensing electrode is applied by colloidal spray deposition. Both electrodes are sintered in air. The sensor configuration is shown in Figure 1. Typical electrode microstructure and thickness are shown in Figure 2.

Testing is performed in flowing, room temperature air $(2 \mathrm{l} / \mathrm{min})$ in a quartz tube $(22 \mathrm{~mm}$ I.D.) on the benchtop. Sensor temperature is controlled by an $\mathrm{AC}$ voltage applied to the heating element. $\mathrm{H}_{2}$ and $\mathrm{CH}_{4}$ are added to the flowing air using a standard gas-control system. Humidity is added by flowing the air through a gas bubbler. Sensor response is measured using a Solartron 1260 electrochemical interface.

\section{RESULTS AND DISCUSSION}

The microstructure of the sintered working electrode is shown in Figure 2. The particle size can 
be seen to be extremely fine, $<50 \mathrm{~nm}$, and the electrode thickness is $\sim 4.5 \mu \mathrm{m}$. These characteristics are important to the electrode performance since they affect the gas transfer through the electrode, and the catalytic surface area. Experimental indications are that the electrode thickness, as well as the sensor operating temperature, can significantly affect the cross sensitivity to water [2].

Response to $2000 \mathrm{ppm} \mathrm{H}_{2}$ in flowing air is shown in Figure 3 for the sensor when operated at $460{ }^{\circ} \mathrm{C}$. That temperature was chosen as a suitable trade-off between power consumption $(\sim 5.4 \mathrm{~W})$ and response characteristics. The response is shown for both dry and humid air, $\sim 0$ and $100 \%$ relative humidity, respectively. The time between datum points in the Figure is 0.25 seconds, thus the sensor response is less than 2 seconds under both conditions. This fast response time is an important practical characteristic of the $\mathrm{H}_{2}$ safety sensor. In dry air, the sensor response is substantial, $\sim 200 \mathrm{mV}$ for 1905 ppm for $2000 \mathrm{ppm} \mathrm{H}_{2}$. It can be seen that the baseline recovery after removal of the $\mathrm{H}_{2}$ from the gas stream is fairly slow. This is a consequence of the low operating temperature and is not considered to be important for the safety sensor application. If necessary, however, the baseline recovery can be expedited by transient heating of the sensor to a higher temperature for 10-30 seconds. The elevated temperature would enhance the equilibration kinetics at the electrode surfaces.

Figure 3 also shows the sensor response when the flowing air contains $100 \%$ relative humidity. It is apparent that the presence of the humidity reduces the sensor response slightly and also leads to a less stable (decaying) sensor response. The visible decay in the sensor response is reproducible in the sense that if the $\mathrm{H}_{2}$ flow is terminated for several minutes, and then resumed, the curve in Figure 3 is duplicated. Thus, the process leading to the decaying signal occurs during the $\mathrm{H}_{2} \mathrm{O} / \mathrm{H}_{2}$ exposure and not during exposure to $\mathrm{H}_{2} \mathrm{O}$ by itself. This aspect of the sensor performance, therefore, will not impact the 
safety sensor application because the decay rate of the response is sufficiently slow to allow the sensor system to respond appropriately to the detected $\mathrm{H}_{2}$ concentration.

Sensor response versus $\mathrm{H}_{2}$ concentration is shown in more detail in Figure 4. Again the sensor operating temperature is $460{ }^{\circ} \mathrm{C}$, and the measurements are performed in flowing air. For dry air, the data show a fairly logarithmic relation of sensor response versus $\mathrm{H}_{2}$ concentration. For testing in air containing $100 \%$ relative humidity, the sensor 'response' was designated as the response after $100 \mathrm{~s}$. This allowed for accommodation of the decaying signal, Figure 3, without requiring the long equilibration times for the signal to reach steady state in the humid air. This $100-\mathrm{s}$ time period was selected as sufficient to insure appropriate response of the safety sensor under realistic operating conditions. The data in $100 \%$ relative humidity show a reduction in response, versus that in dry air, ranging from $5 \%$ at $200 \mathrm{ppm} \mathrm{H}_{2}$ to $\sim 15 \%$ at $1000 \mathrm{ppm}$. This differential does not increase significantly with increasing $\mathrm{H}_{2}$ concentration, and under both conditions the response seems to 'saturate' at $\sim 2 \% \mathrm{H}_{2}$. Also shown in Figure 4 is the cross-sensitivity of the sensor to $\mathrm{CH}_{4}$. The data show that the $\mathrm{H}_{2} / \mathrm{CH}_{4}$ selectivity of the sensor ranges from $3 / 1$ to $6 / 1$ (at 2000 and 200 ppm respectively).

\section{CONCLUSION}

An $\mathrm{H}_{2}$ sensor based on an ITO sensing electrode and a YSZ electrolyte is presented. The data show that the sensor has a large response, fast response time, and good selectivity versus $\mathrm{H}_{2}$ and $\mathrm{CH}_{4}$. This sensing approach has significant potential for application as a safety sensor, for example in PEM fuel cell powered vehicles. 


\section{ACKNOWLEDGEMNTS}

The authors wish to thank Rick Soltis, of the Ford Research Center, for supplying the heated substrates used in this investigation. This work was performed under the auspices of the U.S. Department of Energy by the University of California, Lawrence Livermore National Laboratory under Contract No. W-7405-Eng-48.

\section{REFERENCES}

1. Supplied by Rick Soltis, Ford Research Center, Dearborne, MI.

2. To be submitted

\section{FGURE CAPTIONS}

Figure 1: $\mathrm{H}_{2}$ safety sensor prototype showing a) sensing electrode, b) reference electrodes, c) resistive heater, and d) electrical connections. The scale bar at the top is in inches.

Figure 2: SEM micrograph of a typical sensing electrode showing microstructure and thickness.

Figure 3: Response of the sensor, operated at $460{ }^{\circ} \mathrm{C}$, to $2000 \mathrm{ppm} \mathrm{H}_{2}$ in air containing a) $0 \%$ and b) $100 \%$ relative humidity.

Figure 4: Response of the sensor, operated at $460{ }^{\circ} \mathrm{C}$, to a) $\mathrm{H}_{2}$ and b) $\mathrm{CH}_{4}$ in air containing $0 \%$ relative humidity, and c) $\mathrm{H}_{2}$ in air containing $100 \%$ relative humidity. 


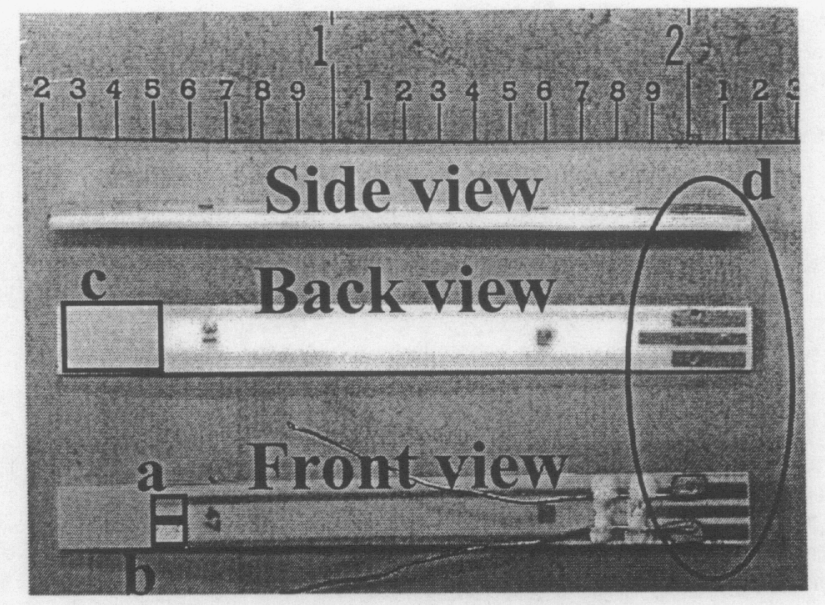




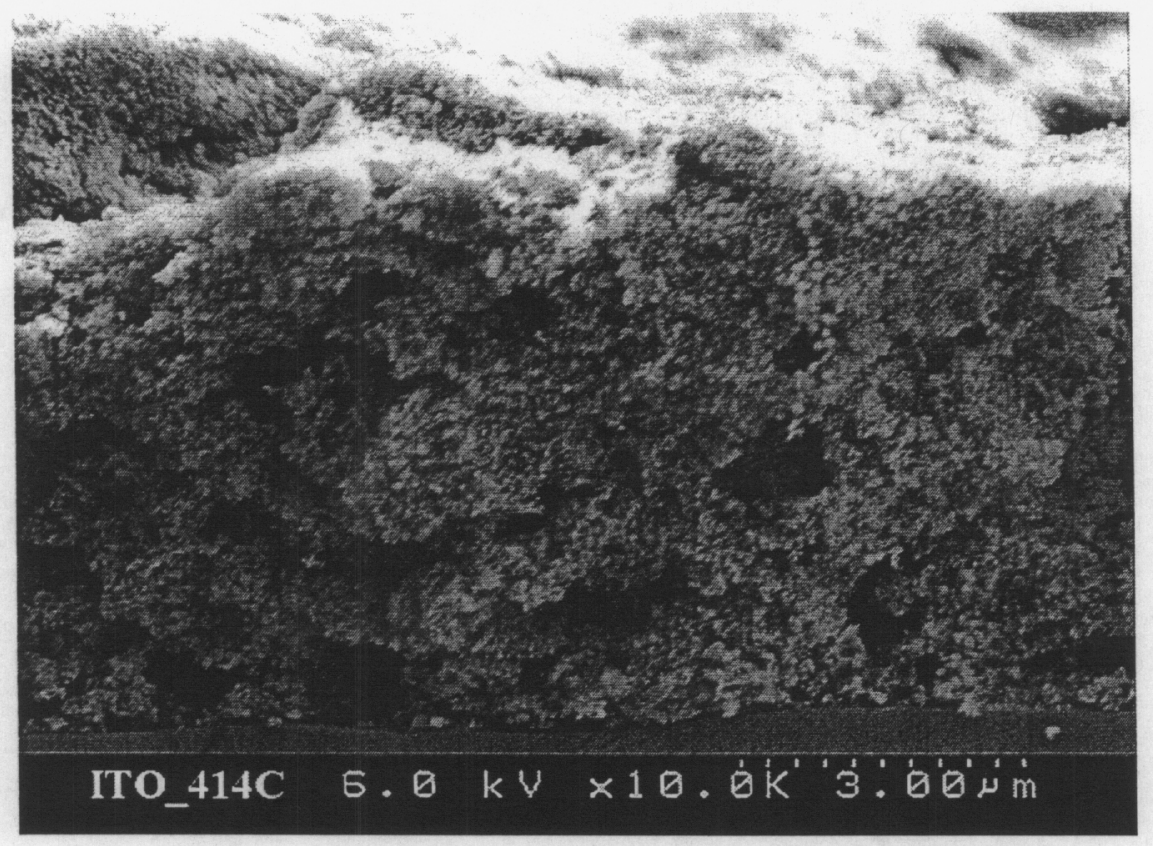




$$
\text { L }
$$




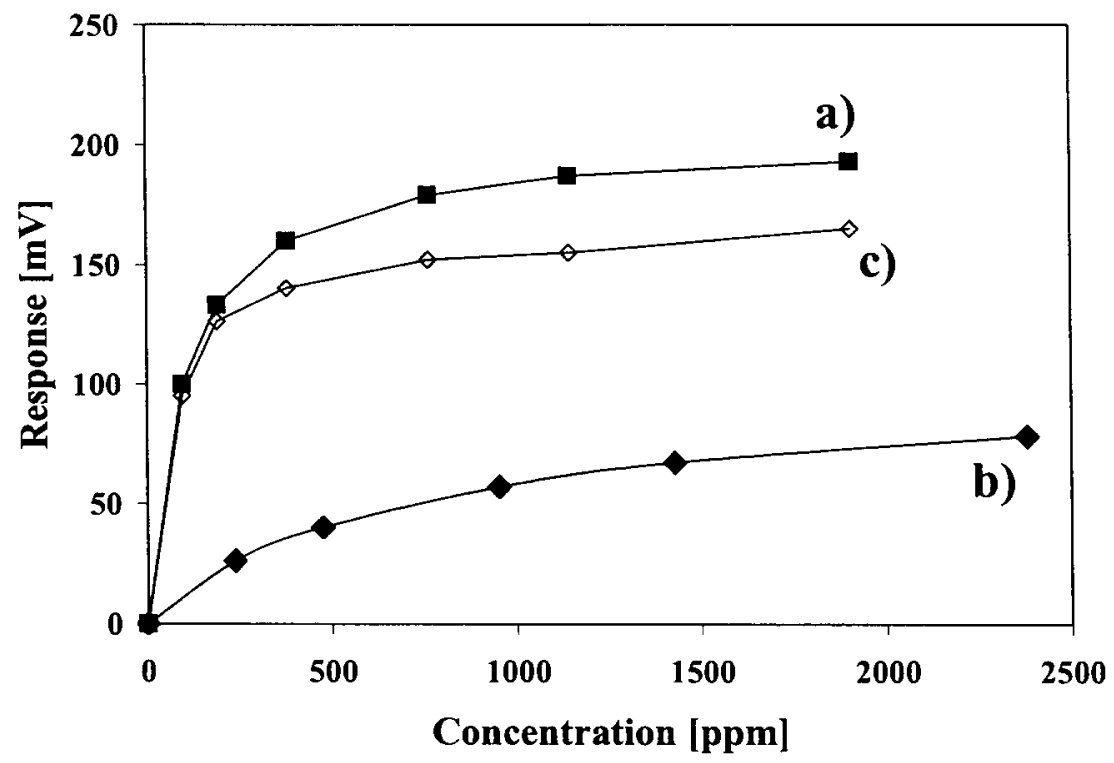

